\title{
Female genital alteration: a compromise solution
}

\author{
Kavita Shah Arora, ${ }^{1,2}$ Allan J Jacobs ${ }^{3}$
}

${ }^{1}$ Department of Obstetrics and Gynecology, MetroHealth Medical Center, Cleveland, Ohio, USA

${ }^{2}$ Department of Bioethics, Case Western Reserve University, Cleveland, Ohio, USA ${ }^{3}$ Director of Gynecologic Oncology at Coney Island Hospital, Professor of Obstetrics and Gynecology and Associate Faculty in Bioethics, Stony Brook University, Stony Brook, New York, USA

\section{Correspondence to}

Dr Kavita Shah Arora, Department of Obstetrics and Gynecology, MetroHealth Medical Center, 2500 MetroHealth Drive, G230E, Cleveland, OH 44109, USA; Kavita.shah.arora@gmail.com

Received 17 July 2014 Revised 24 February 2015 Accepted 21 July 2015

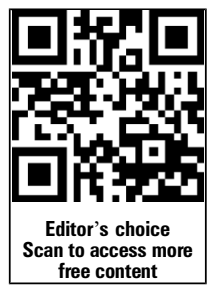

\section{SLinked}

- http://dx.doi.org/10.1136/ medethics-2015-103027

- http://dx.doi.org/10.1136/ medethics-2015-103029

- http://dx.doi.org/10.1136/ medethics-2015-103030

- http://dx.doi.org/10.1136/ medethics-2015-103206

- http://dx.doi.org/10.1136/ medethics-2015-103376

\section{CrossMark}

To cite: Arora KS, Jacobs AJ. J Med Ethics 2016;42:148-154.

\section{ABSTRACT}

Despite 30 years of advocacy, the prevalence of nontherapeutic female genital alteration (FGA) in minors is stable in many countries. Educational efforts have minimally changed the prevalence of this procedure in regions where it has been widely practiced. In order to better protect female children from the serious and longterm harms of some types of non-therapeutic FGA, we must adopt a more nuanced position that acknowledges a wide spectrum of procedures that alter female genitalia. We offer a revised categorisation for nontherapeutic FGA that groups procedures by effect and not by process. Acceptance of de minimis procedures that generally do not carry long-term medical risks is culturally sensitive, does not discriminate on the basis of gender, and does not violate human rights. More morbid procedures should not be performed. However, accepting de minimis non-therapeutic $f$ FGA procedures enhances the effort of compassionate practitioners searching for a compromise position that respects cultural differences but protects the health of their patients.

Procedures that surgically alter the external genitalia of children are quite common throughout the world, though the distribution varies greatly by geography. The majority of male children in America are circumcised. ${ }^{1}$ While non-therapeutic female genital alteration (FGA) procedures in children are unusual in the USA, an estimated $80-140$ million women throughout Africa, the Middle East, India and South-East Asia have had such procedures. $^{2} 3$ The WHO, American Academy of Pediatrics (AAP), and the American Congress of Obstetricians and Gynecologists (ACOG) have policies in place to support circumcision; however, FGA has been deemed a human rights violation by these same organisations as well as by the United Nations. $^{2-4}$ In fact, the US government has expressly outlawed any procedure that incises or changes a female child's external genitalia in the absence of medical indications. ${ }^{5}$

While years of advocacy and legislation aimed at eliminating non-therapeutic procedures on female external genitalia has resulted in a decline in the prevalence of the practice, the magnitude of this decline has been soberingly small. In Egypt, the percentage of women who had any procedure that altered external genitalia performed on a daughter only fell from $77.8 \%$ to $71.6 \%$ over 5 years from 2006 to 2011. This relatively small decrease in prevalence was associated with minimal change in attitude towards the procedures. ${ }^{6}$ In a study in Somalia, the country in the world with the highest prevalence of these procedures, $81 \%$ of subjects underwent infibulation and only 3\% did not have
FGA. Eighty-five per cent had an intention to subject their daughters to an extensive FGA procedure, and 90\% supported the continuation of the practice. ${ }^{7}$ There have been some more encouraging studies, however. In Kenya, for example, prevalence has dropped from $49 \%$ in women ages $45-49$ years to $15 \%$ in girls ages $15-19$ years and in Liberia, the prevalence has dropped from $85 \%$ to $44 \%$, respectively. ${ }^{8} 9$

Immigrants to Western nations may continue to subject their daughters to genital alteration, ${ }^{10-12}$ though the frequency is difficult to assess. While laws enacted in these countries make procedures that alter a female's external genitalia illegal, they may in some instances worsen health outcomes by driving the practice underground by sending female children to Africa or by inviting circumcisers to the West. ${ }^{11}$ Making the practice illegal also hampers the ability to study the actual incidence and effects of these procedures, limits an open dialogue regarding changing the practice, and may impede efforts to voluntarily reduce the incidence of these procedures (thereby improving public health). ${ }^{13}{ }^{14}$ This local culture of silence is due to a distrust of the global eradication campaigns as being 'sensationalized, ethnocentric, racist, culturally insensitive and simplistic'. ${ }^{15}$

Since progress in reducing FGA procedures has been limited in states where they are endemic and the commitment of people from these cultures to these procedures has led to their persistence in states where they are legally discouraged, alternative approaches should be considered. ${ }^{7}$ To accommodate cultural beliefs while protecting the physical health of girls, we propose a compromise solution in which liberal states would legally permit de minimis FGA in recognition of its fulfilment of cultural and religious obligations, but would proscribe those forms of FGA that are dangerous or that produce significant sexual or reproductive dysfunction.

Regrettably, academic and public health consideration of non-therapeutic FGA has been hampered by several issues. First, there is no recognised nomenclature based on the functional effects of each of the several procedures that may be employed to alter female genitalia. Second, discussion often is infused with a strong cultural and gender bias against FGA in all forms. Third, grouping all forms of FGA in discourse and condemnation assumes that all FGA procedures carry the same risks, which is medically inaccurate. Finally, authors arguing against all forms of FGA construe the concepts of beneficence and non-maleficence narrowly with regard to their scope, and too broadly with regard to their applicability. On the 
one hand, they argue that physical well-being trumps social and cultural well-being. On the other hand, they argue that concepts originally used to apply to the actions of physicians are equally applicable to parents.

We are not arguing that any procedure on the female genitalia is desirable. We are also not suggesting that people whose beliefs or sense of propriety leads them to perform these procedures on their children would necessarily accept alterations in their practices to conform to the authors' views of what is acceptable. Rather, we only argue that certain procedures ought to be tolerated by liberal societies. We hold that the ethical issues are no different for procedures that are performed as cultural or religious expressions by a minority group than for procedures that are performed for aesthetic reasons by members of a mainstream culture. Finally, we believe that all procedures should be performed with adequate analgesia. FGA is a highly complex issue. In some forms, it is deeply rooted in traditions of female submission to their male counterparts. We by no means condone oppression. Given that most communities that practice FGA also practice male circumcision, some forms of FGA reflect cultural norms of gender differentiation that are more pronounced than in Western society. However, in order to reduce the prevalence of the extensive forms of FGA, we propose a compromise solution that is ethical, culturally sensitive and practical.

We will begin by discussing nomenclature, then describe the various types of FGA and classify them according to their effects. This revised classification will rationalise discussion of the subject, and should prove useful even to those who disagree with our conclusions. After discussing the medical safety of FGA procedures, we will argue that liberal governments should tolerate de minimis procedures with no more effect than other accepted procedures performed on minors for aesthetic enhancement. Finally, we will argue that labelling these de minimis procedures as 'mutilation' is culturally insensitive and discriminatory towards women, and that they do not constitute a human rights violation. In doing so, we offer a tiered argument and compromise solution-First, given that the more extensive forms of FGA are physically harmful and may constitute oppression towards women, these practices should be actively discouraged by means such as education, social pressure, regulation and prohibition. Second, since progress at eradicating the extensive forms of FGA has been slow and the de minimis alternate procedures are not associated with the same risks of long-term harm, these should be encouraged as a compromise solution that upholds cultural and religious practices without sacrificing the health and well-being of female children.

We acknowledge that issues of cultural sensitivity and gender discrimination in the disparate treatment of male circumcision and FGA could also be treated by proscribing both, instead of the position for which we are advocating. In fact, many have criticised male circumcision as a human rights violation due to the lack of autonomous decision-making and the irreversible nature of the procedure. ${ }^{16-18}$ However, we have argued elsewhere that male circumcision does not constitute a human rights violation. ${ }^{19}$ It is not within the scope of this paper to re-examine this argument or discuss the ethics of male circumcision. However, we will assume the validity of this position for the sake of argument and will argue that a liberal society that tolerates expression of culture and/or religion in the manner of male circumcision should also permit certain de minimis FGA procedures. We believe this is an appropriate assumption because all Western nations in fact permit ritual circumcision of men.

\section{NOMENCLATURE}

We use the term 'procedure' in the context of FGA rather than 'surgery' to emphasise that there is no medical benefit established by well designed trials, and that the primary purpose is not health-related. 'Procedure' is defined by Merriam-Webster as a "series of steps followed in a regular definite order," and does not imply that the intervention is done for health reasons, in a health facility or by a medical professional. ${ }^{20}$ The terms 'surgery' and 'operation,' however, connote a medical context. Much as circumcision performed by a mohel, ear piercing done at a mall, or tattoo performed at a tattoo parlour follow a series of steps in a regular, definite order, morphological alterations of the female external genitalia are also procedures, whether or not performed by a medical professional or in a health facility.

Many terms have been used to describe the procedures that alter female external genitalia, such as 'female circumcision,' 'female genital cutting,' 'female genital alteration,' 'female genital surgery,' and 'female genital mutilation'. ${ }^{13} 1421$ 'Female circumcision' has been abandoned as critics of the procedures felt it conferred the greater 'respectability' of male circumcision. ${ }^{21}$ We agree that the word circumcision should be confined to men as it applies to a specific procedure, whereas procedures on female external genitalia encompass a wide variety of distinct procedures. Also, circumcision potentially confers health benefits on the male child and on his future sexual partners. ${ }^{1} 419$ While health benefits may be a component behind the motivation for FGA, there is a paucity of empirical data supporting this and the primary advantages are aesthetic as well as compliance with religious or cultural norms. ${ }^{22}$ Second, since the majority of procedures are not being performed in hospitals or by trained healthcare professionals, 'female genital surgery' is an inappropriate term, since it inaccurately implies a medical context. $^{21}$

While 'female genital mutilation' is the term currently used most widely by international health and policy organisations, it inappropriately conflates all procedures that alter female external genitalia, while not accounting for their disparate risk profiles. Reclassifying procedures based on their impact rather than the process (as we introduce below), allows for a more informed and clear discussion of these procedures. Female genital mutilation is not an appropriate term to use for de minimis procedures. These procedures are equivalent or less extensive than male circumcision in procedure, scope and effect. Indeed, they are equivalent or less extensive than orthodontia, breast implantation or even the elective labiaplasty for which affluent women pay thousands of dollars. Furthermore, a nick that heals completely is not mutilation in that there is no morphological alteration.

While we acknowledge that critics of male circumcision may label it as 'mutilation' as well, ${ }^{23}{ }^{24}$ it is important to note that the procedure is supported by AAP, ACOG and WHO. Thus, in a liberal society that accepts male circumcision, room for discussion surrounding the acceptability of FGA exists. Calling such elective genital procedures 'mutilation' prejudges the appropriateness of the procedures, thereby precluding discussion. Use of this term precludes discussion of their acceptability in any context, even those that are safe and respectful of an individual's culture. Charged rhetoric such as 'mutilation,' that portrays de minimis procedures as the product of a savage and uncivilised culture, is unworthy of academic discourse. Thus, we prefer 'non-therapeutic FGA,' which is value-neutral, allowing for discourse and potentially, compromise solutions. 


\section{CLASSIFICATION OF NON-THERAPEUTIC FGA PROCEDURES}

It is essential to describe FGA procedures in a way that is accurate and allows people with different viewpoints to discuss issues respectfully. There are a myriad of ways various cultures alter female external genitalia. These range from minimal to markedly invasive and dangerous. ${ }^{25}$ The categorisation currently used by medical and public health organisations is as follows: Type I includes removal of the prepuce or clitoral hood with or without clitorectomy. Type II is the removal of the entire clitoris as well as part or all of the labia minora. Type III, known as infibulation, is the most severe form and involves the removal of the labia majora and/or labia minora, possible removal of the clitoris, and stitching together of the vulvar tissue to cover the urethra and introitus, leaving only a small opening for urine, menstrual flow and intercourse. Finally, Type IV includes pricking, nicking or incisions of the external genitalia, stretching of the clitoris or labia, cauterisation or the introduction of corrosive substances into the vagina. 2526

However, this categorisation inadequately reflects the consequences to the recipient of the procedure. It has also not aided in discussion because of the wide variety of procedures included in each category, as well as due to omissions of some procedures altogether. We therefore propose a new categorisation that is based on the effects of the procedure, rather than the process. Given that it is the health consequences of these procedures that are the most worrisome to international health groups, it is logical to group the procedures based on these effects, rather than groups of procedures with a wide range of resultant consequences within each group.

Category 1 includes procedures that should almost never have a lasting effect on morphology or function if performed properly. A small nick in the vulvar skin fits into this category. Category 2 consists of procedures that create morphological changes, but are not expected to have an adverse effect on reproduction or on the sexual satisfaction of the woman or her partner. Examples include surgical retraction of the clitoral hood or procedures resembling elective labiaplasty as performed in Western nations. Surgical resection of the clitoral hood is the vulvar procedure that most closely resembles male circumcision. Category 3 contains those procedures that are likely to impair the ability of the recipient to engage in or enjoy sexual relations. Clitorectomy, whether partial or complete, falls into this category. Category 4 contains procedures likely to impair reproductive function, either by reducing the chances of conception or by making vaginal delivery more dangerous. Infibulation is an example. Category 5, advanced only for the sake of completeness, contains any procedure that is likely to cause other major physiological dysfunction or death, even if performed correctly. To our knowledge, there are no FGA procedures that fall into this category.

Due to a lack of data regarding the specific risks and outcomes with each FGA procedure, it may be difficult to accurately assign specific procedures to these categories. Being criminal in Western societies, they have not been studied systematically. However, Type 1 and 2 procedures have counterparts in Western gynaecology. Accidental traumatic lacerations of the labia majora are not uncommon. While longer and deeper than a controlled nick, and not created under clean conditions, they almost always heal without sequelae. ${ }^{27}$ It is reasonable to assume that a nick from a scalpel would do likewise. The similarity of removal of the clitoral hood to male circumcision and of labial excision to aesthetic labial reduction procedures is sufficiently close that the effects can reasonably be considered identical pending empirical proof. At the other end of the spectrum, the more extensive procedures such as infibulation are associated with risks such as severe bleeding, infection, obstructed labour, dyspareunia, depression and post-traumatic stress disorder. $^{28} 29$

We acknowledge three shortcomings of this classification. First, it is not entirely stable; procedures could shift from one category to another if the common understanding of their effect changes. Second, there may not be agreement on the effects. Finally, procedures are grouped in their anticipated risk profile, not in the actual risk profile for each patient. For example, while infibulation is likely to cause long-term sexual and reproductive health impairments, it does not normally lead to death and therefore is not placed in that category. That is not to say it does not ever lead to death, but the anticipated impact is not death.

\section{MEDICAL SAFETY}

Of course, the issue of harm is the heart of the distinction in the categorisation of FGA that we propose. While any procedure is associated with several predictable short-term risks (namely bleeding and infection), the long-term sequelae should be rare for Category 1 and Category 2 procedures. In a WHO study, there were no statistically significant differences in health outcomes between those women that underwent Type I surgery (equivalent to our Category 2) and those that had no surgery. ${ }^{14}$ In fact, our classification scheme would exclude clitorectomy (included in the current Type I procedures) from this category and thus further decrease the risks of the procedure. This is in stark contrast to the risks of Category 3 and 4 procedures which are severe: obstructed labour, caesarean section, postpartum haemorrhage, $80 \%$ risk of flashbacks, depression, $30 \%$ risk of post-traumatic stress disorder and death from sepsis. ${ }^{18} 29$

Critics of FGA have pointed out that there is no medical benefit to factor in the risk versus benefit calculus so often used in medicine and when compared with male circumcision. ${ }^{29}$ However, up to recently, the medical benefits of male circumcision were also thought to be tenuous, contested or so minor that circumcision was classified as an elective, cosmetic procedure. ${ }^{1}$ Thus, disallowing Categories 1 and 2 of FGA because it lacks medical benefit is an unjust and inappropriate hurdle to legalisation.

Jacobs's three-pronged test has been previously proposed that, if satisfied, would morally preclude a government or regulatory agency from reversing a parental decision to involve a child in a minority group practice. First, the practice in question must not significantly burden either society or its members outside the group. Second, the practice must not (A) create burdens that a reasonable person outside the group would not accept for himself, or that a reasonable parent would not accept for her child (such as child marriage or slavery); or (B) carry a substantial chance of death or of major disruption of a physiological function. Third, the burden on society or individuals must be actual and substantial, and not hypothetical or unlikely. All of these criteria must be satisfied if a government is to tolerate the practice, and we argue that governments should tolerate procedures under these circumstances. Categories 1 and 2 of FGA (but not Categories 3-5) fulfil these criteria and thus, a government or regulatory agency does not have a medical basis for interfering with a parental decision to practice a cultural or religious belief. ${ }^{30}$

\section{ETHICAL UNDERPINNINGS}

The standard that guides ethical and legal decision-making on behalf of children is the best interests standard. ${ }^{31}$ Unfortunately, the standard is conclusory rather than definitive. At least in 
USA, the best interests of a child are determined by judicial and quasi-judicial decisions in individual cases, rather than arising from an established heuristic that would almost always predict the decision prospectively. Furthermore, in the USA, the courts either balance the interests of the child against parental beliefs and rights, as established by three key Supreme Court decisions, ${ }^{32-34}$ or rebuttably presume that the interests of the child are congruent with the parents' beliefs. In using the best interests standard, we are including prepubertal children, in whom any decision is made exclusively by the child's proxy, as well as adolescents, in whom ethical paediatric decision-making requires assent to the procedure. We acknowledge that not all procedures (eg, Category 2 procedures such as removal of the clitoral hood or labia minora) are technically feasible or commonly performed in prepubertal children. The best interests of a child encompass physical well-being, and social, economic, psychological and spiritual well-being. That the human rights movement accepts this view is clear from documents such as the Convention on the Rights of the Child, which does not privilege the physical well-being of children over other types of well-being. ${ }^{35}$

Second, analysis of issues in medical ethics generally regards principles as being prima facie in nature, rather than absolute. Therefore, important emotional and social considerations can trump minor medical considerations. Third, the transactional costs of governmental action to stop parents from subjecting children to these procedures must be considered. For this reason, the Royal Dutch Medical Society stopped short of advocating that male circumcision be outlawed for fear that the practice would be driven underground. ${ }^{36}$ Compounding the potential for FGA practices to be driven underground, is the fact that the remedy for violation of laws limiting genital procedures on minors will have a direct or indirect adverse impact on the child. Whether parents who otherwise are uncontroversially adequate, are fined, imprisoned or lose parental rights because they subject their children to FGA, the child will suffer.

Therefore, we must ask what harm is befalling the child. Procedures that compromise sexual function, sexual enjoyment and reproductive capacity clearly violate the best interest of the child. De minimis procedures such as removal of the clitoral hood or a ritual nick on the external female genitalia (Categories 1 and 2) cause little or no functional harm. Therefore, it is difficult to characterise them as unethical or a human rights violation. If these procedures are not unacceptable on beneficence or maleficence grounds, and the imposition on the child's autonomy is no greater than the imposition that is currently accepted for other procedures or non-physical interventions whose effect is of equal or greater magnitude, then there are no reasonable autonomy grounds for restricting the procedure.

We re-emphasise that we do not support the more severe FGA procedures (Categories 3-5), nor would we diminish international efforts to end the practice of these procedures, with their resultant harm to sexual and reproductive function. We believe it is ethically appropriate to work for their elimination through the legal system as well as through educational and grass-roots efforts, for the sake of the female children that are subjected to these dangerous procedures. ${ }^{37}$ However, Category 1 and Category 2 procedures do not reach the threshold of a human rights violation. Opposition to these de minimis procedures on female genitalia inhibits the effort of compassionate practitioners searching for a compromise procedure to respect the culture but safeguard the health of their patients..$^{15} 38$ Indeed, by preventing such compromise, absolutists may create further harm to children. Instead of receiving Category 1 or 2 procedures, girls may continue to receive more extensive procedures underground in the USA or in their home countries because there is no safe alternative.

\section{CULTURAL SENSITIVITY}

FGA is 'embedded in many cultural systems through multiple ties to historical tradition, tribal affiliation, social status, marriageability and religion,' but is most frequently associated with Muslim culture. ${ }^{39}$ Critics have argued that there is no reference to any procedure altering female external genitalia in the Quran and thus, there is no religious basis for the practice. ${ }^{38}$ However, legal protection of a religious practice is not contingent either on the orthodoxy of the practice or on a consensus within a religious tradition accepting the practice. Furthermore, outsiders to a religious tradition cannot infer the practices of a religious system from a literal reading of its canonical texts. It is no more possible to define Islam within the four corners of the Quran than to define Christianity (which includes traditions ranging from Presbyterian to Pentecostal to Greek Orthodoxy) solely from a reading of the Bible. Rather, the content of religious belief and practice are guided by interpretive texts and traditions. Thus, many Muslim scholars classify FGA as 'Sunnab' or practice established by the prophet Muhammad. Though not prescribed explicitly in the Quran, the practice thus is religiously virtuous. In fact, the colloquial term for FGA procedures in Arabic refers to a ritual state of purity. ${ }^{38}$

FGA also has strong cultural ties that are not explicitly religious. While objectionable to some Western feminists, marriage is associated strongly with quality of life in these traditions. In some cultural milieus, a woman who has not undergone a procedure to alter her external genitalia may find it difficult to marry. ${ }^{38}$ Additionally, there may be an aesthetic component to labiaplasty as practiced in some societies. ${ }^{40}$ Contrary to the picture painted by many international organisations, then, it could be stated that "children [undergo FGA procedures] because their parents love them and want them to be happy in their adult lives". ${ }^{38}$ By labelling FGA as female genital mutilation, our discussions run the risk of demonising important cultural practices. ${ }^{15}$

It is important to note that the debate does not need to simply distil to the irreconcilable positions of cultural relativism and universalism. ${ }^{2}{ }^{41}$ Rather, we can invoke universally shared values against long-term harm and thus continue to advocate for the cessation of Categories 3 and 4 of FGA. This is the same rationale used for authorising blood transfusions on the children of Jehovah's Witnesses-that is, irrespective of culture, the risk of long-term harm is sufficient that society's mandate can ethically outweigh cultural interests. ${ }^{42}$ It is important to ensure, however, that the discourse remains sensitive to and respectful of the voices of the women who experience these practices, and that we take into account historical relationships of power so that we can arrive at a nuanced and balanced solution. ${ }^{2}{ }^{15}$ One of the responses to the current strategy of charged rhetoric has been a cultural backlash or a 'defense of traditions by African women against what is perceived as Western cultural imperialism' and thus, the lack of sensitive discourse is not productive towards reaching a compromise solution. ${ }^{38}$

Policies that attempt to suppress all forms of FGA that alter female external genitalia are culturally supremacist. Members of a majority culture are more likely to consider their own practices voluntary, reasonable and even desirable, while perceiving minority practices (such as FGA by female African Muslims) as unreasonable, coercive and unacceptable. ${ }^{30} 38$ The tolerant 
attitude in the USA to male circumcision is in stark contrast to its treatment of FGA. ${ }^{5}$ Yet, 'both are likely voluntary choices influenced by cultural conditioning, ${ }^{30}$ In a liberal society, then, government and regulatory agencies should tolerate minority practices unless they cause substantial damage to society and its members. While Categories 3, 4 and 5 of FGA cause harm and thus should not be tolerated, Categories 1 and 2 do not and thus should be approached from a culturally tolerant perspective that acknowledges a parental right to raise a child according to the parents' own religious and cultural customs, which are well established in American law. ${ }^{32-34}$ In the USA, the Federal Prohibition of Female Genital Mutilation Act, which was enacted in 1996, is deliberately worded broadly enough to not differentiate between the categories of FGA. The law is likely unconstitutional and should be altered to allow for religious and cultural freedom for a safe procedure that does not result in long-term harm. ${ }^{4} 38$

\section{GENDER DISCRIMINATION}

We approach this subject with the understanding that most of the cultures and communities that practice FGA also practice male circumcision. To the extent that Category 1 and Category 2 procedures are intended to curb sexual desire, the same is true of comparable procedures performed on boys. The balance of medical evidence demonstrates that male circumcision does not negatively affect male sexuality, though the data are neither consistent nor methodologically optimal. ${ }^{19} 3543$ Similarly, by definition, these de minimis female procedures do not curb sexuality; if they did they would be Category 3. The goal of curbing sexual desire is debateable, but if it applies to men and women there are no discrimination issues. Furthermore, if a procedure intended to curb sexual desire does not, in fact, do so, then restricting it assumes low priority.

To the extent that gender discrimination is present, it lies in restrictive policies towards Categories 1 and 2 of FGA. Laws that prohibit these procedures and international advocacy against them are culturally insensitive and supremacist and discriminatory towards women. Male circumcision is legal in USA and tolerated in most of the world, even when done by nonmedical practitioners in the home. ${ }^{38}$ Yet comparable or less radical procedures in women are deemed misogynistic and human rights violations. ${ }^{38} 44$ Feminists trying to protect women in these cultures are mistaking Categories 1 and 2 of FGA as an example of male domination in philosophical and practical terms.

Categories 1 and 2 of FGA have been called misogynistic because the aim is usually to curb female sexuality and thus oppress women. However, if removal of the prepuce curbs sexuality (as has been argued, though contrary to the best evidence), then male circumcision should be viewed as misandrist. ${ }^{45} 46$ If we are not willing to label male circumcision as misandrist because it affirms males in the eyes of their cultural and religious communities, then the same should be true of Categories 1 and 2 of FGA in that it affirms women in the cultures and religions practicing FGA. If, on the other hand, removal of the prepuce does not curb sexuality, then the basis for claiming the practice as misogynistic is invalidated. ${ }^{44}$ In summary, the de minimis procedures do not oppress as much as they differentiate and thus should be tolerated.

These asymmetrical judgments based on gender also have practical consequences which, paradoxically, decrease women's control over their bodies. FGA is typically 'controlled and managed by women'. ${ }^{14}$ Data reveal that women in many of these cultures favour the continuance of FGA equally or at an even higher rate than the men in these cultures. ${ }^{14} 38$ Laws to ban FGA are enacted by predominantly male legislatures and enforced by predominantly male police. Furthermore, it is almost exclusively women who are penalised for the crime of FGA in areas it has been outlawed. All this further brings women's bodies under male religious and political control, thus disempowering the very women feminists are hoping to protect. $^{1438}$

\section{HUMAN RIGHTS VIOLATION}

Finally, the International Federation of Gynecology and Obstetrics as well as WHO have labelled all forms of FGA as a human rights violation as it violates bodily integrity in the absence of any medical benefit' and victimises vulnerable girls. ${ }^{47}$ However, male circumcision is also a procedure that violates bodily integrity and up to recently was thought not to have justifiable medical benefit-but was instead tolerated due to religious and cultural freedom and the lack of long-term harm. Thus, Categories 3, 4 and 5 of FGA are certainly human rights violations as they violate bodily integrity and cause long-term harm (but not because they lack medical benefit). Other examples of procedures that lack medical benefit but are not classified as human rights violations that society accepts (though perhaps does not ethically condone) include piercings, cosmetic surgery, removal of an asymptomatic ganglion cyst, etc. Also, neonatal boys are certainly just as vulnerable as girls. In fact, one could argue that the pubescent or adolescent girl undergoing FGA is more capable of assenting to the procedure and claiming the culture/religion as her own, than the neonatal boy. ${ }^{5}$ We do not condone the forcible practice of FGA if a child developmentally capable of providing assent declines to do so.

In analysing the putative harm done by rites involving genital procedures, we must ask ourselves whether it actually is harmful in the eyes of the people involved, or whether the harm is perceived only by people who view the situation from a different perspective. The concept of liberalism in various Western societies involves a spectrum ranging from those who advocate widespread freedom, tolerating government interference only to remedy the threat or actuality of serious harm; to those who advocate government mobilisation of physical, legal and educational resources to promote a thick agenda expressed in the international Human Rights proclamations adopted after World War II, but actually reflecting the nation's own values and prejudices. Recognising that a society is entitled to protect its own values, even if these are not universal values, we nevertheless believe that it is rarely appropriate for governments to intrude into familial, cultural and religious practices that create little tangible harm.

Finally, while parenthood certainly does not connote unrestricted ownership, Categories 1 and 2 of FGA should not be considered child abuse. Permanent injury does not result from these procedures and thus parents should be granted latitude in terms of the decisions they make in the best interest of their children. If FGA is viewed culturally as a means to moral or ritual purity, then it could be argued that parents are acting in the best interest of their children by partaking in procedures that uphold these beliefs but do not cause long-term harm. In Western pluralistic society, where reasonable people may disagree regarding the best interest of a child in terms of the calculus of medical risks and non-medical benefits, parents should be granted wide authority for determining whether or not to perform Categories 1 and 2 of FGA insofar as the state's or society's interest of ensuring that no long-term harm is committed is met. ${ }^{1} 15$ 
To summarise, in a liberal society, arguments supporting de minimis FGA fall into at least three areas. The first is based on individual rights of parents. The second is based on respect for minority cultures. The last is based on the concept that government should exercise restraint if fundamental interests of society are not at stake.

\section{UTILITARIAN CONSIDERATIONS}

Even if one were to reject all of the arguments proposed so far, toleration of de minimis procedures is warranted. This is because it is necessary to protect girls. There is reason to believe that some communities that practice Categories 3 and 4 of FGA will accept de minimis procedures in their stead. In 1996, physicians at Harborview Medical Center in Seattle which served a large Somali population, after much deliberation, decided to offer a ritual nick under analgesia to adolescent girls able to assent to the procedure. This compromise was reached in partnership with the Somali patient population with the knowledge that if the alternative and safe procedure would not be able to be performed in the USA, the women would take their female children back to Somalia for a more extensive, likely Category 4 procedure.

Against this background, the AAP's Committee on Bioethics issued an opinion stating that genital nicking was ethically acceptable. It stated that AAP "opposes all types of female genital cutting that poses risks of physical or psychological harm". It further stated that the ritual nick is not physically harmful, is a compromise that that "may build trust between hospitals and immigrant communities", may save some girls from undergoing more extensive and damaging procedures and "play a role in the eventual eradication" of female genital cutting. $^{21}$

In both cases, thoughtful physicians confronted first-hand by girls with FGA sought a reasonable way to bridge the 'impasse between respecting cultural diversity and promoting basic human rights'. ${ }^{2}$ However, each of these two attempts was met with brisk and severe resistance by critics of FGA that believed such a compromise would 'handicap health and government workers in stamping out the more horrible forms of this practice'. ${ }^{38}$ Paradoxically, this is more likely to perpetuate destructive Category 3 and Category 4 procedures than to decrease them. The media and public outcry of utter condemnation led Harborview to end the compromise. ${ }^{38}$ As for the AAP change in position, swift, negative reactions from the media, human rights organisations and advocacy groups resulted, in which it was reiterated that all forms of FGA were human rights violations and that the global advocacy efforts aimed at eradicating FGA was weakened by AAP's new stand. AAP retracted its statement and again adopted strong opposition to all female genital cutting, removed its endorsement of the clitoral nick and educated its members not to perform such ritual procedures. ${ }^{25} 4849$

Such opposition to Category 1 nicking sacrifices the needs of actual individuals to the imperatives of ideology. We believe that such opposition to Category 1 and Category 2 procedures that are acceptable to some populations that practice FGA are more likely to perpetuate the medically deleterious Category 3 and Category 4 procedures rather than aid in eradicating them. We acknowledge that our proposed strategy may be mistaken or misconveyed to grant a sense of acceptability to all FGA procedures. ${ }^{49}$ Careful policy and advocacy efforts, however, can assist in conveying the stark difference between Category 1 and Category 2 procedures versus those in Category 3 and Category 4. A second criticism of such a strategy that 'opens the door' is that it is difficult prevent more invasive procedures from being done under the guise of de minimis procedures or regulate the amount of tissue being removed. However, given the widespread nature currently of Categories 3 and 4 of FGA, if even a few girls undergo a de minimis procedure instead of a more invasive one due to this strategy, than the strategy is appropriate. The concern regarding amount of tissue being removed is also not unique to FGA, but is similar to male circumcision as well as cosmetic surgeries on adults. Furthermore, the advocacy efforts aimed at completely eliminating FGA have had only limited success; therefore, a new strategy is required that accounts for cultural requirements while safeguarding the health of female children. ${ }^{7}$ If a girl, by undergoing a small vulvar nick in infancy, forestalls subsequent vulvar infibulation done under dangerous conditions, we would consider this a worthwhile trade-off.

\section{CONCLUSION}

This 'complex cross-cultural issue cannot be adequately dealt with by a simple condemnation' and any impetus to end FGA must come from within the religions and cultures that practice it. $^{250}$ By working together respectfully with, and not independently of, local communities we can offer and promote the alternative of Categories 1 and 2 of FGA as a compromise that respects culture and religion but provides the necessary protections against child abuse. ${ }^{2} 38$ Critics of FGA worry that a compromise position of accepting de minimis procedures weakens the effort to eliminate FGA completely. ${ }^{51}$ Yet, despite 30 years of advocacy, we have not made dents in the prevalence of the practice in many countries and have been largely unable to change the attitudes regarding the acceptability of FGA. The goal of eradicating procedures that do not cause significant harm is at worst, morally questionable and at best, an invitation to waste resources that could be applied to ends that are more likely to further human well-being. In order to better protect female children from the long-term harms of Categories 3 and 4 of FGA, we must adopt a more nuanced position that acknowledges that Categories 1 and 2 are different in that they are not associated with long-term medical risks, are culturally sensitive, do not discriminate on the basis of gender and do not violate human rights.

Acknowledgements The authors thank Insoo Hyun, PhD for his valuable feedback and critical reading of this manuscript.

Contributors Both authors are responsible for the design, drafting and editing of this manuscript. KSA is responsible for the overall manuscript.

Competing interests None declared.

Provenance and peer review Not commissioned; externally peer reviewed.

\section{REFERENCES}

1 Task force on circumcision. Male circumcision. Pediatrics 2012;130:e756-85.

2 Lane SD, Rubinstein RA. Judging the other. Responding to traditional female genital surgeries. Hastings Cent Rep 1999;26:31-40.

3 World Health Organization. Female genital mutilation and other harmful practices: Prevalence of FGM. 2014. http://www.who.int/reproductivehealth/topics/fgm/ prevalence/en/ (accessed 25 Oct 2014).

4 Task force on circumcision. Circumcision policy statement. Pediatrics 2012;130:585-6.

5 Solomon LM, Noll RC. Male versus female genital alteration: differences in legal, medical, and socioethical responses. Gend Med 2007;4:89-96.

6 Hassanin IMA, Shaaban OM. Impact of the complete ban on female genital cutting on the attitude of educated women from Upper Egypt toward the practice. Int J Gynaecol Obstet 2013;120:275-8.

7 Gele AA, Bo BP, Sundby J. Have we made progress in Somalia after 30 years of interventions? Attitudes towards female circumcision among people in the Hargeisa district. BMC Res Notes 2013:6:122

8 Cappa C, Moneti F, Wardlaw T, et al. Elimination of female genital mutiliation/ cutting. Lancet 2013;382:1080-1. 
9 Gulland A. Fewer younger women are undergoing female genital mutilation, a study finds. BMJ 2013;347:f4754.

10 Johansson J. Methods for the prevention of female genital cutting in Finland. Finnish J Ethn Migration 2008;3:96-8.

11 Leye E, Powell RA, Nienhuis G, et al. Health care in Europe for women with genital mutilation. Health Care Women Int 2006:27:362-78.

12 Leye E, Deblonde J, García-Añón J, et al. An analysis of the implementation of laws with regard to female genital mutilation in Europe. Crime Law Soc Change 2007;47:1-31.

13 Iyioha I. Public health, cultural norms and the criminal law: an inconvenient union? A case study of female genital cutting. Med Law 2012;31:451-72.

14 The Public Policy Advisory Network on Female Genital Surgeries in Africa. Seven things to know about female genital surgeries in Africa. Hastings Cent Rep 2012;6:19-27.

15 Khaja K, Lay K, Boys S. Female circumcision: towards an inclusive practice of care. Health Care Women Int 2010;31:686-99.

16 Darby RJ. The child's right to an open future: is the principle applicable to non-therapeutic circumcision? J Med Ethics 2013;39:463-8.

17 Frisch M, Aigrain Y, Barauskas V, et al. Cultural Bias in the AAP'S 2012 technical report and policy statement on male circumcision. Pediatrics 2013;131:796-800.

18 Svoboda JS. Circumcision of male infants as a human rights violation. J Med Ethics 2013;39:169-474.

19 Jacobs AJ, Arora KS. Ritual infant circumcision and human rights. Am J Bioeth 2015;15:30-9.

20 "Procedure." Merriam-Webster.com. 2011. http://www.merriam-webster.com (accessed 18 Feb 2014).

21 Committee on Bioethics. Ritual genital cutting of female minors. Pediatrics 2010;125:1088-93.

22 Svoboda R, Darby JS. A rose by any other name? Rethinking the similarities and differences between male and female genital cutting. Med Anthropol Q 2007;21:301-23.

23 Hellsten SK. Rationalising circumcision: from tradition to fashion, from public health to individual freedom - critical notes on cultural persistence of the practice of genital mutilation. J Med Ethics 2004;30:248-53.

24 Legato MJ. Rethinking circumcision: medical intervention, religious ceremony, or genital mutilation? J Gend Specif Med 2002;5:8-10.

25 Committee on Bioethics. Female genital mutilation. Pediatrics 1998;102:153-6.

26 Nour NM, Michels KB, Bryant AE. Defibulation to treat female genital cutting: effect on symptoms and sexual function. Obstet Gynecol 2006;108:55-60.

27 Spitzer RF, Kives S, Caccia N, et al. Retrospective review of unintentional female genital trauma at a pediatric referral center. Pediatr Emerg Care 2008;24:831-5.

28 Chibber R, El-Saleh E, El Harmi J. Female circumcision: obstetrical and psychological sequelae continues unabated in the $21^{\text {st }}$ century. J Matern Fetal Neonatal Med 2011;24:833-6.
29 International Society for Sexual Medicine. ISSM position statement-female genital cutting. J Sex Med 2012;9:1744.

30 Jacobs AJ. The ethics of circumcision of male infants. Isr Med Assoc J 2013;15:60-5.

31 American Medical Association. Opinion 10.016: Pediatric Decision-Making. Code of Medical Ethics. 2011.

32 Meyer v. Nebraska, 262 US 390 (1923).

33 Pierce v. Society of Sisters, 268 US 510, (1925).

34 Troxel v. Granville, 530 US 57, 68-69 (2000).

35 N.A. Convention on the rights of the child. United Nations General Assembly, 1989. http://www.ohchr.org/en/professionalinterest/pages/crc.aspx (accessed 18 Feb 2014).

36 Koninklijke Nederlandsche Maatschappij tot bevordering der Geneeskunst. The non-therapeutic circumcision of male minors. 2010. http://knmg.artsennet.nl/ Publicaties/KNMGpublicatie/Nontherapeutic-circumcision-of-male-minors-2010.htm (accessed 18 Feb 2014).

37 Macklin R. Aesthetic enhancement? Or human rights violation? Hastings Cent Rep 2012;42:28-9.

38 Davis DS. Male and female genital alteration: a collision course with the law? Health Matrix 2001;11:487-570.

39 Berg RC, Denison E. A tradition in transition: factors perpetuating and hindering the continuance of female genital mutilation/cutting (FGM/C) summarized in a systematic review. Health Care Women Int 2013;34:837-59.

40 Shweder RA. The goose and the gander: the genital wars. Global Discourse 2013;3:348-66.

41 Biller-Andorno N, Wild V. The ethics of evidence. Hastings Cent Rep 2012;42:29-30

42 Committee on Bioethics. Religious objections to medical care. Pediatrics 1997;99:279-81.

43 Bossio JA, Pukall CF, Steele $S$. A review of the current state of the male circumcision literature. J Sex Med 2014;11:2847-64.

44 Benetar M, Benetar D. Between prophylaxis and child abuse: the ethics of neonatal male circumcision. Am J Bioeth 2003;3:35-48.

45 Bronselaer GA, Schober JM, Meyer-Bahlburg HF, et al. Male circumcision decreases penile sensitivity as measured in a large cohort. BJU Int 2013;111:820-7.

46 Senkul T, Iseri $C$, Sen $B$, et al. Circumcision in adults: effect on sexual function. Urology 2004;63:155-8.

47 FIGO Committee Report. Female genital cutting. Int J Gynaecol Obstet 2006;94:176-7.

48 Board of Directors. Ritual genital cutting of female minors. Pediatrics 2010;126:191.

49 MacReady N. AAP retracts statement on controversial practice. Lancet 2010;376:15

50 Nour NM. Using facts to moderate the message. Hastings Cent Rep 2012;42:30-1.

51 Toubia NF. Evolutionary cultural ethics and the circumcision of children. In: Male and female circumcision. USA: Springer, 1999:1-7. 